\title{
Treatment of Carpal Instability and Distal Radioulnar Joint Instability
}

David Meng Kiat Tan, MBBS (Singapore), MMED Surgery (Singapore)*, Jin Xi Lim, MBBS (Singapore), MMED Surgery (Singapore)

\section{KEYWORDS}

- Carpal instability • Scapholunate instability • Perilunate instability • Distal radioulnar joint instability

\section{KEY POINTS}

- Carpal instability and distal radioulnar joint instability is said to be present when the wrist exhibits symptomatic malalingment, abnromal kinematics and is unable to bear loads.

- The different forms of carpal instability can be classified according to different stages. This correlates well with pathoanatomy and serves as a guide to treatment.

- Stress radiography and fluoroscopy can be used to aid in the diagnosis of dynamic carpal instabilities whilst arthroscopy offers the most accurate assessment of these conditions.

- Distal radioulnar joint instability can result from injuries to the triangular fibrocartilage complex, an abnormal joint architecture or alterations in the radioulnar relationship from forearm fractures and malunion.

- The treatment of distal radioulnar joint instability without arthritis should address the TFCC and/or the bony relationship of the joint. When arthritis has developed, a salvage procedure is indicated.

Video content accompanies this article at http://www.plasticsurgery.theclinics.com.

\section{CARPAL INSTABILITY}

Carpal instability can occur after trauma, remotely after trauma, and sometimes without trauma. The 3 most important conditions are scapholunate instability, lunotriquetral instability, and perilunate instability complex. The carpus is considered unstable if it exhibits symptomatic malalignment, is not able to bear loads, and does not have normal kinematics during any portion of its arc of motion. ${ }^{1}$

\section{Classification}

Although a majority of carpal instabilities arise from trauma, there are 6 important categories to consider when analyzing carpal instability ${ }^{2}$ (Table 1). There are 4 patterns of instability that have been described by various investigators ${ }^{3-5}$ and are widely accepted (Fig. 1).

Carpal instability dissociative (CID) refers to instability within a row of carpal bones, such as scaphoid fractures or scapholunate dissociation in the proximal row. Carpal instability nondissociative (CIND) is instability between rows either at the radiocarpal joint (eg, radiocarpal fracture dislocations) or midcarpal joint (eg, midcarpal instability). Carpal instability combined/complex $(\mathrm{CIC})$ is a combination of CID and CIND, such as perilunate dislocations (PLDs). Carpal instability adaptive

Disclosures: The authors have nothing to disclose.

Department of Hand and Reconstructive Microsurgery, National University Hospital Singapore, 1E Kent Ridge

Road, Tower Block, Level 11, Singapore 119228, Singapore

* Corresponding author.

E-mail address: david_mk_tan@nuhs.edu.sg 


\begin{tabular}{|c|c|c|c|c|c|}
\hline $\begin{array}{l}\text { Category } \\
\text { I-Chronicity }\end{array}$ & $\begin{array}{l}\text { Category } \\
\text { II-Constancy }\end{array}$ & $\begin{array}{l}\text { Category } \\
\text { III-Etiology }\end{array}$ & $\begin{array}{l}\text { Category } \\
\text { IV-Location }\end{array}$ & $\begin{array}{l}\text { Category } \\
\text { V-Direction }\end{array}$ & $\begin{array}{l}\text { Category } \\
\text { VI-Pattern }\end{array}$ \\
\hline $\begin{array}{l}\text { Acute, }<1 \text { wk } \\
\text { (maximum healing } \\
\text { potential) }\end{array}$ & $\begin{array}{l}\text { Predynamic } \\
\text { Dynamic }\end{array}$ & $\begin{array}{l}\text { Congenital } \\
\text { Traumatic }\end{array}$ & $\begin{array}{l}\text { Radiocarpal } \\
\text { Intercarpal }\end{array}$ & $\begin{array}{l}\text { VISI } \\
\text { DISI }\end{array}$ & $\begin{array}{l}\text { CID } \\
\text { CIND }\end{array}$ \\
\hline $\begin{array}{l}\text { Subacute, } 1-6 \mathrm{wk} \\
\text { (some healing } \\
\text { potential) }\end{array}$ & & $\begin{array}{l}\text { Inflammatory } \\
\text { Arthritis } \\
\text { Neoplastic }\end{array}$ & $\begin{array}{l}\text { Midcarpal } \\
\text { Carpometacarpal }\end{array}$ & $\begin{array}{l}\text { Ulnar } \\
\text { Radial }\end{array}$ & $\begin{array}{l}\mathrm{ClC} \\
\mathrm{ClA}\end{array}$ \\
\hline $\begin{array}{c}\text { Chronic, }>6 \text { wk (poor } \\
\text { healing potential) }\end{array}$ & & $\begin{array}{l}\text { latrogenic } \\
\text { Miscellaneous }\end{array}$ & $\begin{array}{l}\text { Specific bones/ } \\
\text { ligaments }\end{array}$ & $\begin{array}{l}\text { Ventral } \\
\text { Rotatory }\end{array}$ & \\
\hline
\end{tabular}

(CIA) refers to carpal malalignment in adaption to extracarpal changes (eg, carpal collapse in malunited distal radius fractures).

\section{Critical Imaging Studies}

\section{Plain film radiography}

On the posteroanterior (PA) projection, 3 smooth arcs, termed Gilula lines, ${ }^{6}$ can be traced (Fig. 2A). A disruption of any arc suggests the presence of carpal instability (Fig. 2B, C). Loss of carpal height indicates carpal instability with carpal collapse (Fig. 2D).

A well-taken lateral projection shows the axes of the radius and carpal bones (Fig. 3A-D), which form several important indices (Fig. 3E-G). Abnormal indices indicate static carpal malalignment and instability. The term, volar intercalated segmental instability (VISI), is used when the radiolunate angle exceeds $15^{\circ}$ volarly (Fig. 4A) and typically is seen in lunotriquetral dissociation, whereas the term, dorsal intercalated segmental instability (DISI), is for when that angle exceeds $15^{\circ}$ dorsally and most commonly is seen in scapholunate dissociation (Fig. 4B).

\section{Stress radiography}

Stress views are useful for diagnosing dynamic scapholunate instability. A PA clenched fist view with the wrist in neutral, ulnar deviation and radial deviation accentuates the gap/interval between the scaphoid and the lunate (Fig. 5).

\section{Fluoroscopy}

Fluoroscopy is useful to detect subtle dynamic scapholunate and lunotriquetral dissociations. This manifests as a step when axial traction is applied to the wrist (Video 1A). Traction views also are helpful in demonstrating the stage of a PLD and associated bony injuries (Video 1B). In midcarpal instability and other clunking wrist disorders, considerable information can be gleaned by observing the apex of motion at which clunking occurs as the wrist moves from radial to ulnar deviation (Video 2).

\section{MRI}

Powerful magnetic field (3T) MRIs with dedicated wrist coils, thin 1-mm slices, and advanced imaging software make MRI an invaluable noninvasive imaging adjunct for intercarpal ligament injuries and triangular fibrocartilage complex (TFCC) tears.

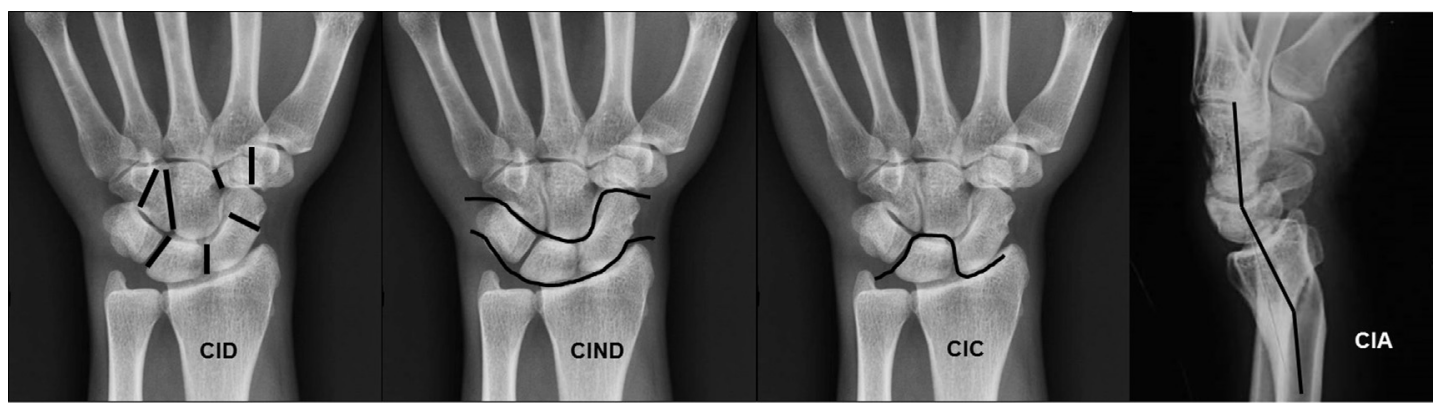

Fig. 1. Four patterns of carpal instability are demonstrated. The bold dark lines indicate potential sites where there is disruption in the continuity of the carpus either through fractures, ligament disruptions, or both. Left panel: Carpal instability dissociative. Left middle panel: Carpal instability non dissociative. Right middle panel: Carpal instability combined/complex. Right panel: Carpal instability adaptive. 

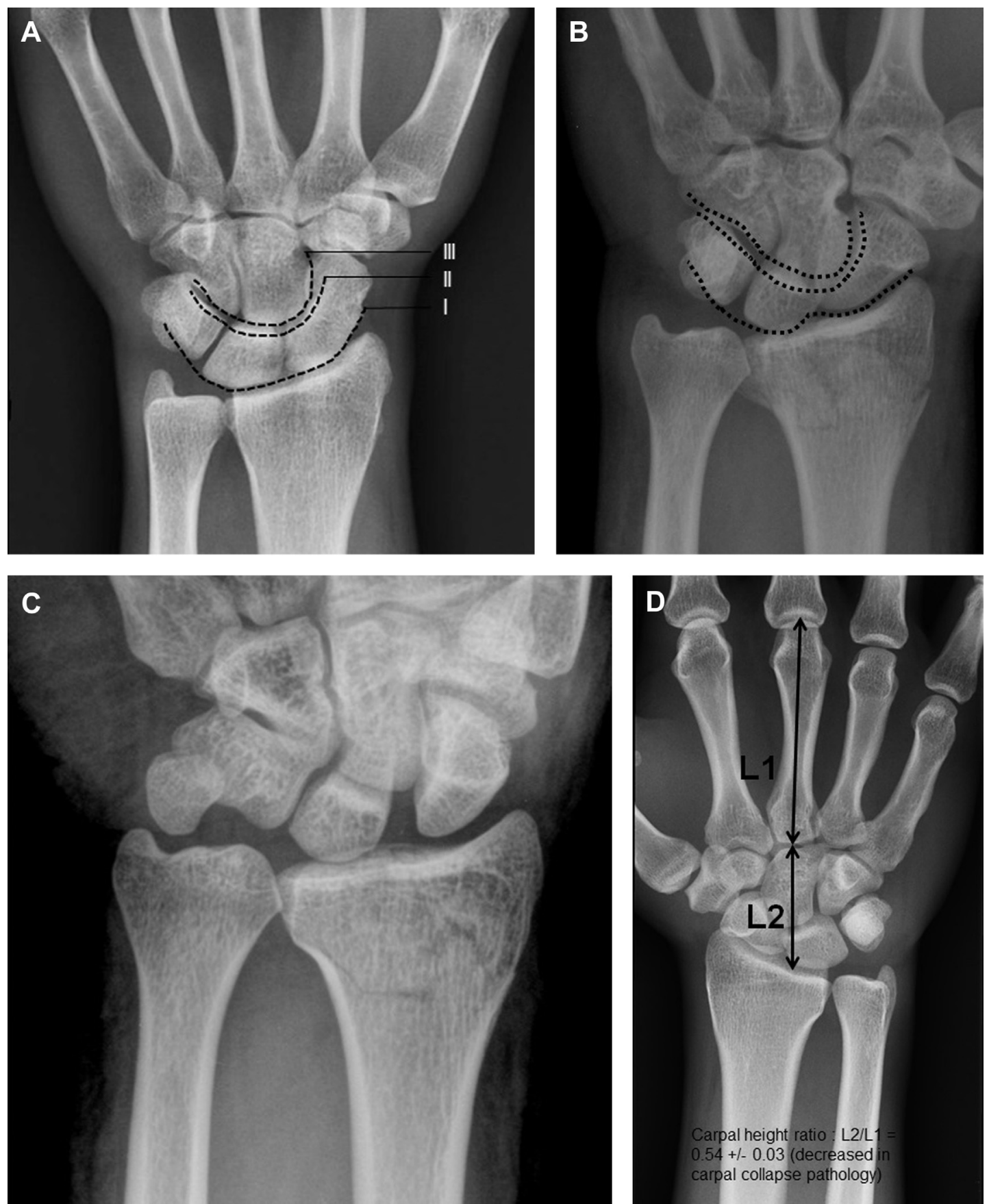

Fig. 2. (A) Gilula lines describe 3 smooth arcs that transcribe the proximal articular surfaces of the proximal carpal row (I), the distal articular surfaces of the proximal carpal row (II), and the proximal articular surface of the hamate and capitate (III). (B) In this minimally displaced distal radius fracture, Gilula first line is broken and is suspicious for a scapholunate ligament injury. $(C)$ Clenched fist view demonstrates widening of the scapholunate interval consistent with a complete tear. (D) Carpal height (L2) and length of third metacarpal (L1). The carpal height ratio $(0.54 \pm 0.03)$ is derived from $\mathrm{L} 2 / \mathrm{L} 1$.

\section{Clinical Conditions}

\section{Scapholunate instability}

Scapholunate instability is the most common form of carpal instability and represents a spectrum of disorders, ${ }^{7}$ ranging from a predynamic state (radiographs normal) to a dynamic state (positive stress radiographs) to a static state (evident on plain film radiography). Left untreated, it may progress to arthritis. 


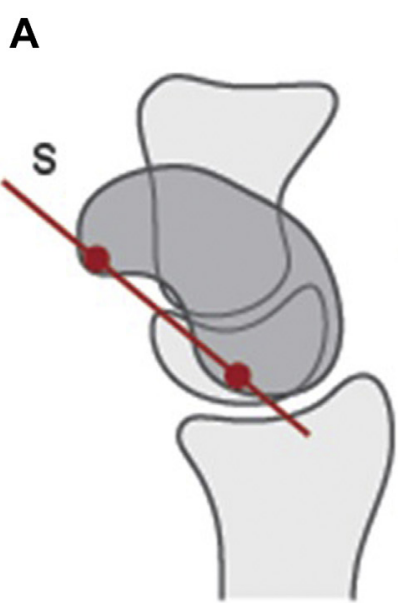

E

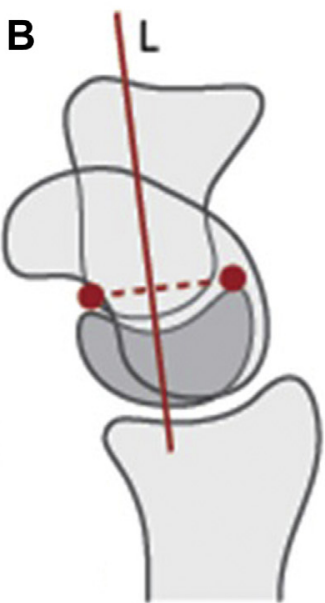

$\mathbf{F}$

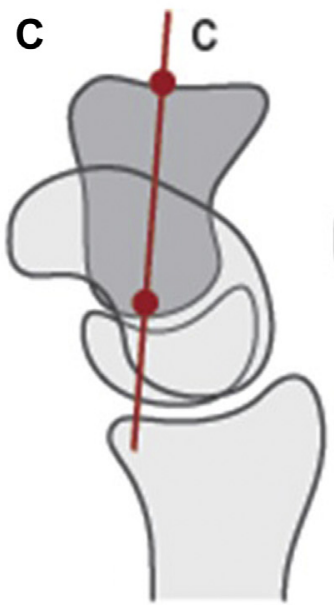

D

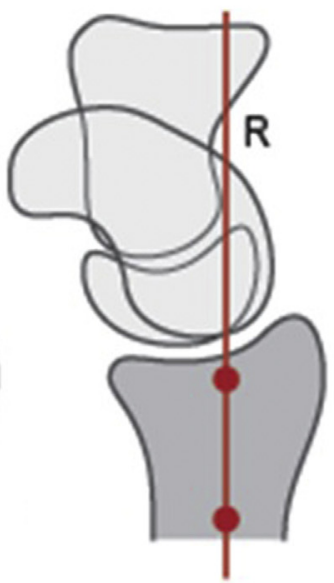

G
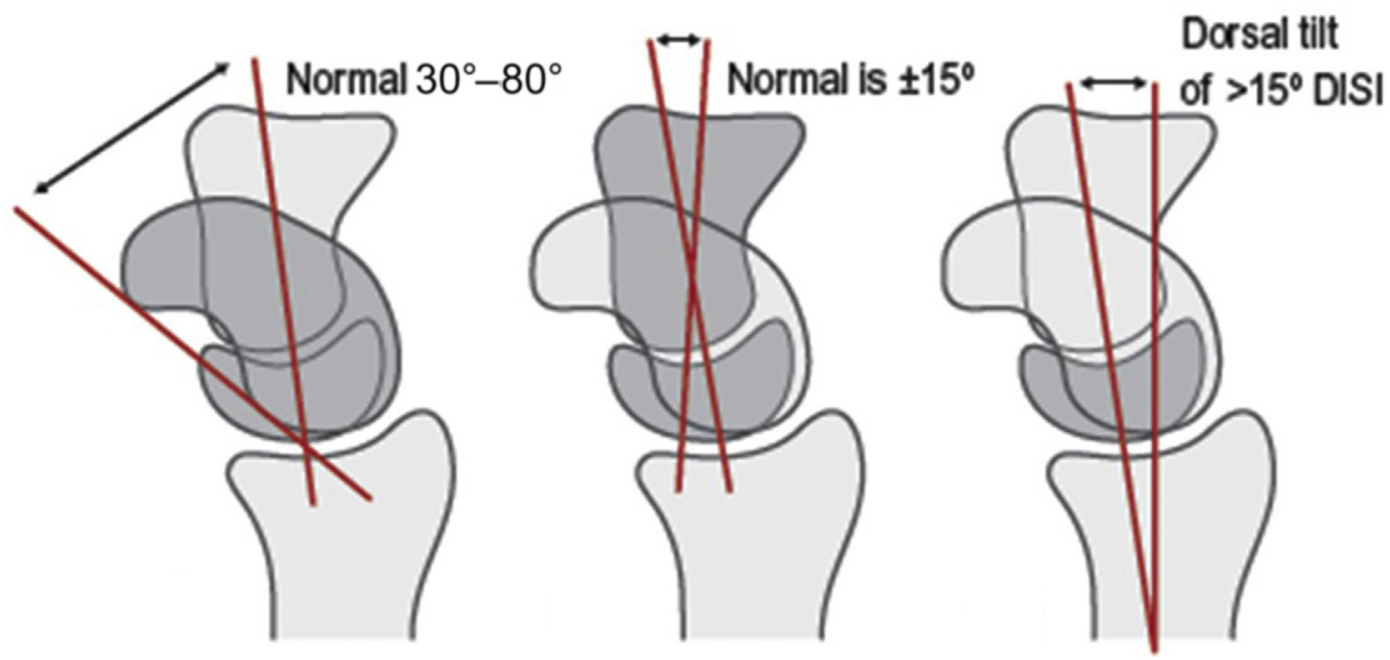

Fig. 3. Demonstrates the axes of the $(A)$ scaphoid $(S),(B)$ lunate $(L),(C)$ capitate $(C)$, and $(D)$ radius $(R)$ from which 3 important indices are determined: $(E)$ scapholunate angle, $(F)$ capitolunate angle, and $(G)$ radiolunate angle. (From Chong AKS, Lim JX, Tan DMK. Diagnostic imaging of the hand and wrist In: Chang J, Neligan PC, eds. Plastic Surgery Volume 6 4th Ed. Philadelphia, PA: Elsevier; 2018: 71-95; with permission.)
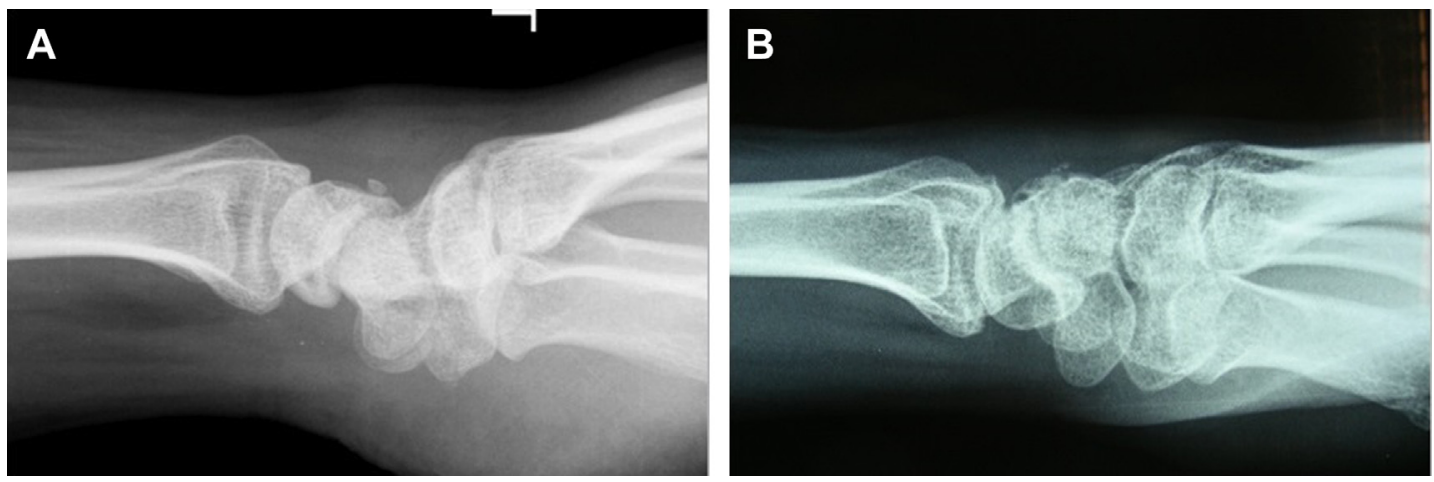

Fig. 4. (A) VISI deformity. (B) DISI deformity with abnormal scapholunate angle. 

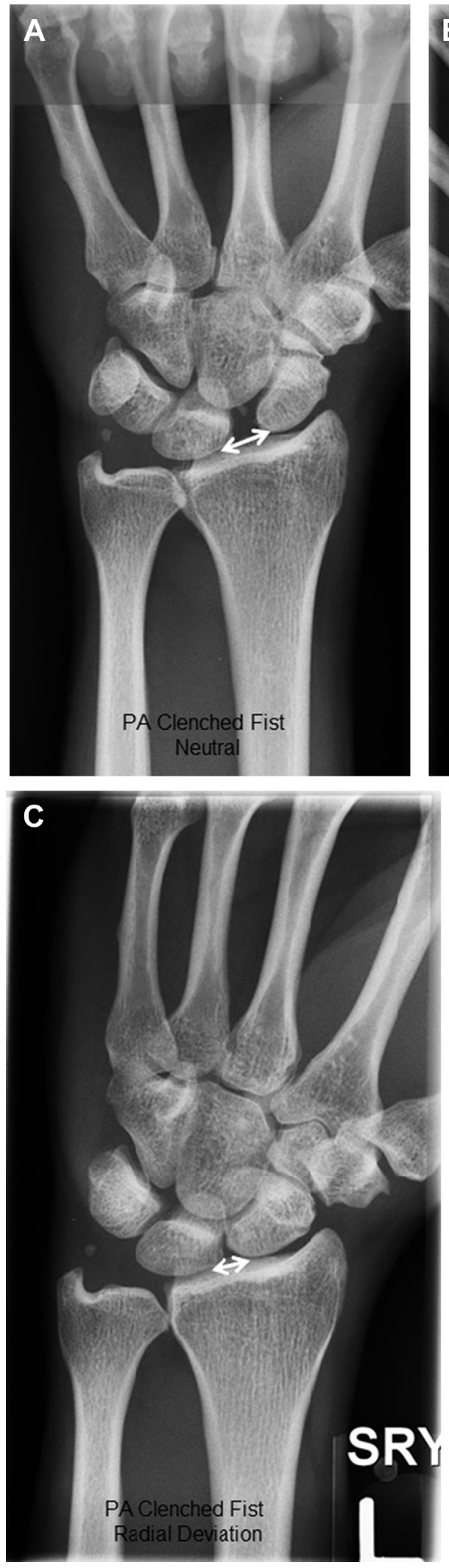

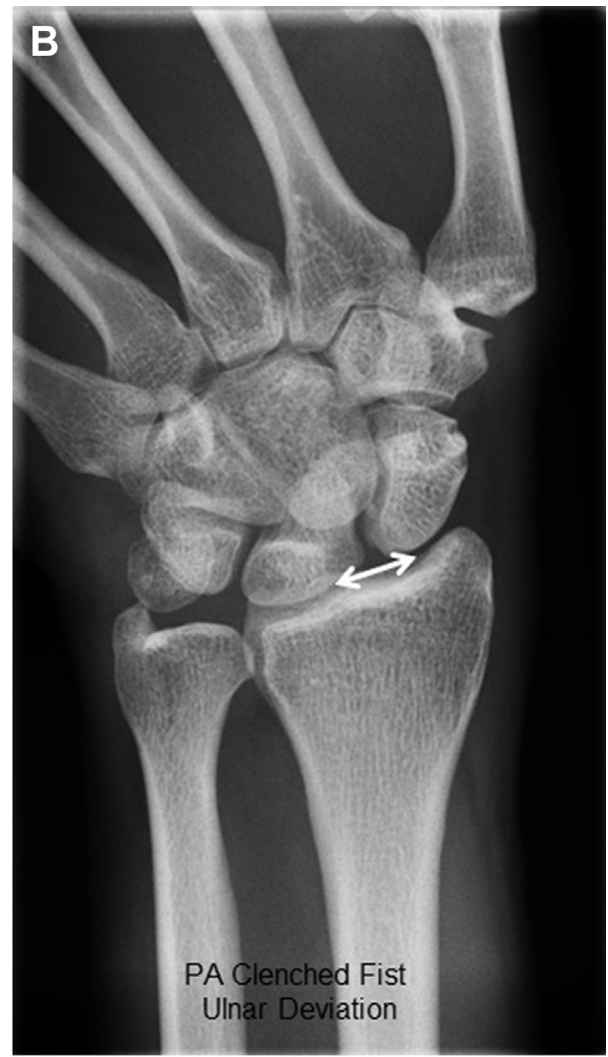

Fig. 5. There is widening of the scapholunate interval $(A)$ in neutral position and when the wrist is $(B)$ in ulnar deviation, which is reduced when the wrist is $(C)$ radially deviated. 
Assessment Pain is typically over the dorsum and dorsoradial aspect of the wrist, aggravated by loading the extended wrist or strenuous activity. This may be preceded by a fall, but a delayed presentation is not uncommon. Other symptoms include clicking of the wrist, weakness of grip, and limitation of motion.

Tenderness may be elicited over the dorsal scapholunate interval $1 \mathrm{~cm}$ distal to Lister tubercle as well as over the tip of the radial styloid, anatomic snuff box, and the scaphoid tubercle. Provocative tests include Watson scaphoid shift (Fig. 6A, B), the resisted finger extension test (Fig. 6C), and a positive scapholunate ballottement test.

Imaging Radiographs may show classic features of an increased scapholunate angle $\left(>70^{\circ}\right)$ and DISI deformity. These features (Fig. 7) are seen with a complete tear of the ligament and failure of the secondary stabilizers. When plain films are normal, stress views should be considered and an MRI may be indicated for further evaluation.
Staging The scapholunate ligament complex has a stout dorsal ligament, modest volar ligament, and weak proximal membranous component. The secondary stabilizers of the scapholunate joint are the dorsal intercarpal, scaphotrapezialtrapezoidal, and radioscaphocapitate ligaments. Disruption of the scapholunate ligament leads to progressive diastasis of the scapholunate interval whereas failure of secondary stabilizers leads to carpal malalignment. Garcia-Elias and colleagues $^{8}$ developed a staging system for scapholunate dissociation based on several factors (Table 2) and proposed treatment accordingly.

Stage 1 (predynamic instability) MRI sometimes may demonstrate a volar or membranous tear; however, arthroscopy is the standard in diagnosing these injuries and may be graded according to the system of Geissler and colleagues ${ }^{9}$ (Table 3; Video 3).

Initial treatment consists of splinting to allow healing in acute and subacute injuries with subsequent proprioception training of the flexor carpi
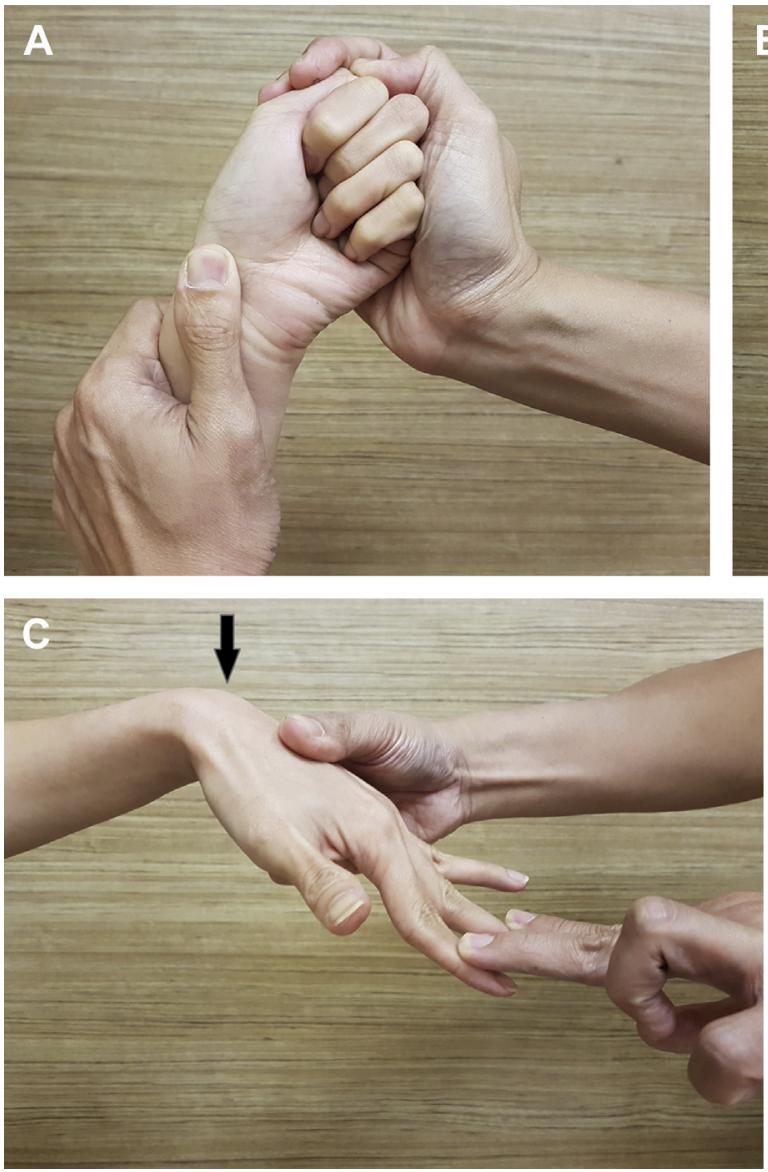

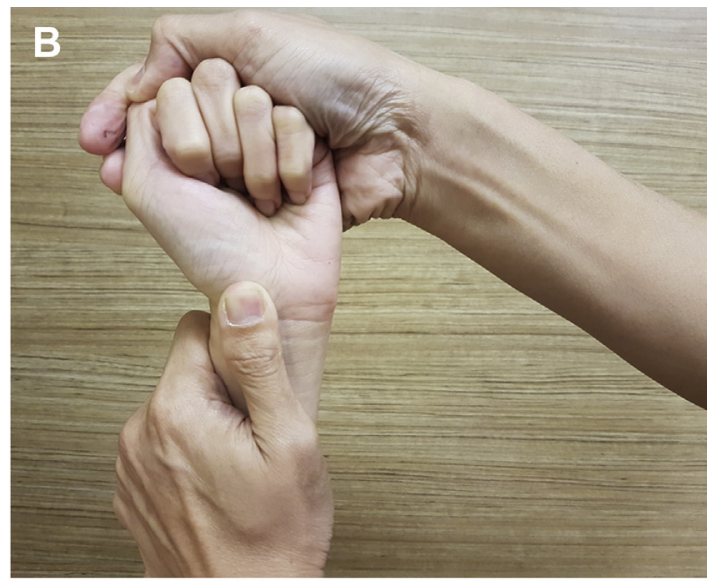

Fig. 6. The patient's wrist is positioned in slight dorsiflexion and the examiner places a thumb over the patient's scaphoid tuberosity and, while maintaining pressure, moves the wrist from a position of ulnar deviation $(A)$ to radial deviation $(B)$ and vice versa. Pain over the dorsal scapholunate interval and an associated clunk constitutes a positive test. Pain without clunking is considered a positive modified Watson scaphoid shift test. (C) The patient's wrist is held partially flexed and the index and middle fingers are extended against the examiner's resisting hand. Pain over the dorsal scapholunate interval (black arrow) is considered a positive test. 

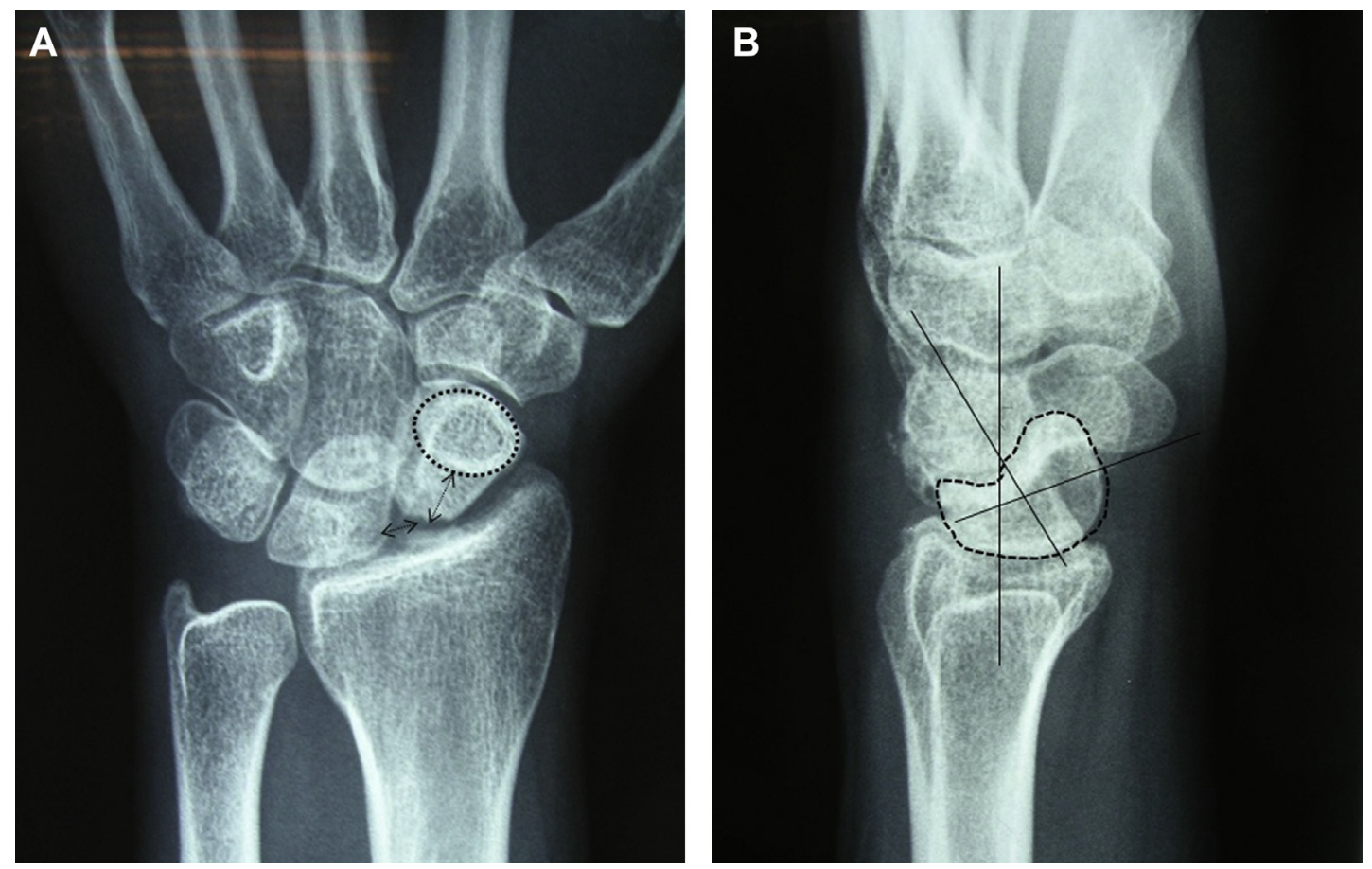

Fig. 7. (A) PA projection of the wrist shows widening of the scapholunate interval greater than $3 \mathrm{~mm}$, a cortical ring sign (signet ring sign), a ring to proximal pole distance less than $7 \mathrm{~mm}$. The lunate appears more rectangular. $(B)$ Lateral projection of the wrist shows the scapholunate angle greater than $70^{\circ}$ and abnormal radiolunate and capitolunate angles.

\begin{tabular}{|c|c|c|c|c|c|c|}
\hline $\begin{array}{l}\text { Scapholunate } \\
\text { Dissociation Stage }\end{array}$ & 1 & 2 & 3 & 4 & 5 & 6 \\
\hline $\begin{array}{l}\text { Is there a partial } \\
\text { rupture with a } \\
\text { normal dorsal } \\
\text { scapholunate } \\
\text { ligament? }\end{array}$ & Yes & No & No & No & No & No \\
\hline $\begin{array}{l}\text { If ruptured, can } \\
\text { the dorsal } \\
\text { scapholunate } \\
\text { ligament be } \\
\text { repaired? }\end{array}$ & Yes & Yes & No & No & No & No \\
\hline $\begin{array}{l}\text { Is the scaphoid } \\
\text { normally aligned } \\
\text { (radioscaphoid } \\
\text { angle } \leq 45^{\circ} \text { )? }\end{array}$ & Yes & Yes & Yes & No & No & No \\
\hline $\begin{array}{l}\text { Is the carpal } \\
\text { malalignment } \\
\text { easily reducible? }\end{array}$ & Yes & Yes & Yes & Yes & No & No \\
\hline $\begin{array}{l}\text { Are the cartilages } \\
\text { at both } \\
\text { radiocarpal and } \\
\text { midcarpal joints } \\
\text { normal? }\end{array}$ & Yes & Yes & Yes & Yes & Yes & No \\
\hline
\end{tabular}

\begin{tabular}{|c|c|}
\hline Grade & Description \\
\hline I & $\begin{array}{l}\text { Attenuation/hemorrhage of } \\
\text { interosseous ligament seen from } \\
\text { the radiocarpal joint; no } \\
\text { incongruency of carpal alignment in } \\
\text { the midcarpal space }\end{array}$ \\
\hline II & $\begin{array}{l}\text { As in grade I, however, incongruency/ } \\
\text { step visible from the midcarpal } \\
\text { joint, with a slight gap less than the } \\
\text { width of a probe }\end{array}$ \\
\hline III & $\begin{array}{l}\text { As in grade II, there also is } \\
\text { incongruency in the radiocarpal } \\
\text { joint, and the probe may be passed } \\
\text { between the carpal bones }\end{array}$ \\
\hline IV & $\begin{array}{l}\text { Obvious incongruency between the } \\
\text { carpal bones and gross instability } \\
\text { with manipulation, and the } 2.7-\mathrm{mm} \\
\text { scope may be passed through the } \\
\text { gap between the carpal bones }\end{array}$ \\
\hline
\end{tabular}


radialis and extensor carpi radialis muscles. Surgery for recalcitrant pain includes arthroscopic interventions, such as débridement alone or with thermal shrinkage and/or pinning, and has $80 \%$ to $90 \%$ success rates.

Stages 2 and 3 In acute complete tears, an open repair is indicated. This may be augmented by a capsulodesis, and the scapholunate and scaphocapitate joints should be pinned with Kirschner wires after reducing the scapholunate angle and scapholunate diastasis (Fig. 8) for 6 weeks. An all-arthroscopic technique of dorsal capsuloligamentous repair ${ }^{10}$ for stages 2,3 , and 4 has been reported, with favorable results across all groups with minimal stiffness at an average of more than 2 years. Open techniques for stage 3 patients include capsulodesis ${ }^{11}$ and bone ligament bone repairs. ${ }^{12}$

Stage 4 Garcia-Elias and colleagues ${ }^{8}$ proposed their triligament reconstruction technique for the stage 4 group of patients using a distally based strip of the flexor carpi radialis tendon to augment the palmar distal connections of the scaphoid, reconstruct the dorsal scapholunate ligament, and reduce the ulnar translocation of the lunate
(Fig. 9). Although efficacious in pain relief and restoration of grip strength, stiffness in the flexion-extension and ulnar deviation plane is notable, and carpal malalignment could be seen to recur early in some instances and was associated with complications. ${ }^{13}$ Other investigators have reported comparable success with capsulodesis ${ }^{11}$ and different forms of tenodesis procedures, including the use of the extensor carpi radialis longus tendon.

Stages 5 and 6 When carpal malalignment is irreducible from chronic injury and scarring of extrinsic capsuloligamentous tissue, scaphotrapeziotrapezoid fusion, ${ }^{14}$ and other forms of intercarpal fusion are indicated. With cartilage loss and arthritis (stage 6), a salvage procedure is indicated, most typically a proximal row carpectomy or a 4-corner fusion if arthritis involves the midcarpal joint.

\section{Lunotriquetral instability}

Lunotriquetral instability remains frequently underdiagnosed, with a paucity of literature regarding its pathogenesis, diagnosis, and treatment. It may occur in isolation as an acute traumatic tear
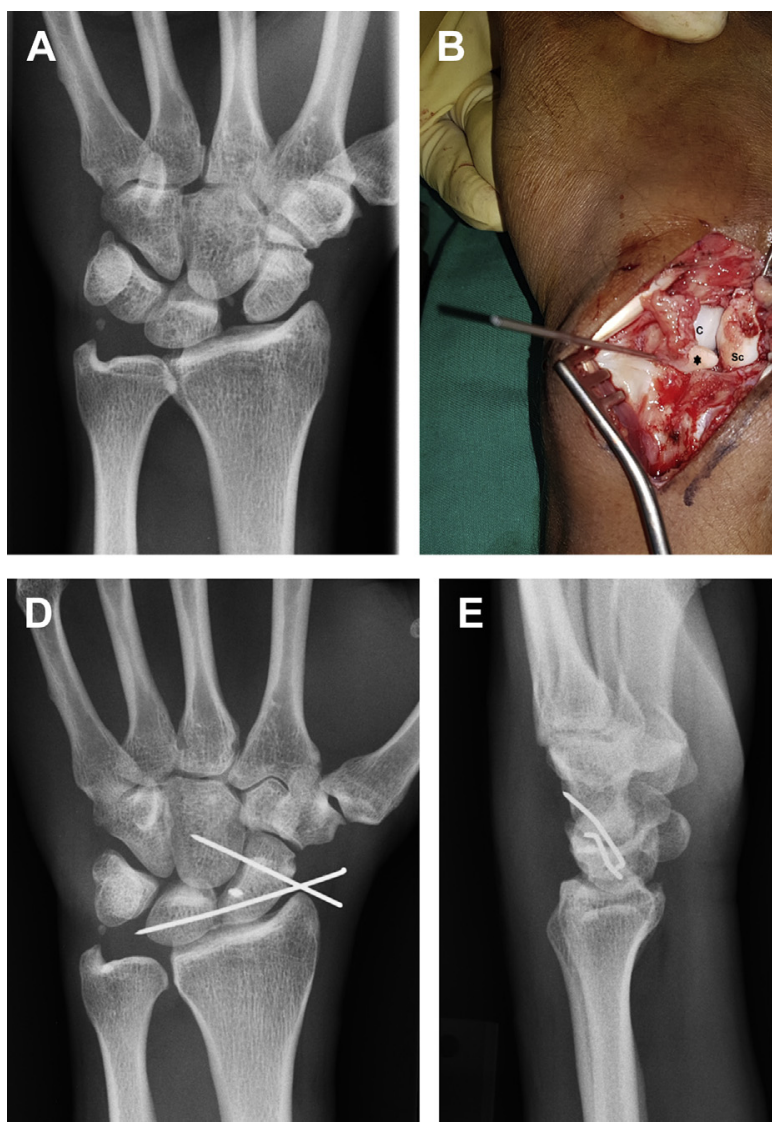

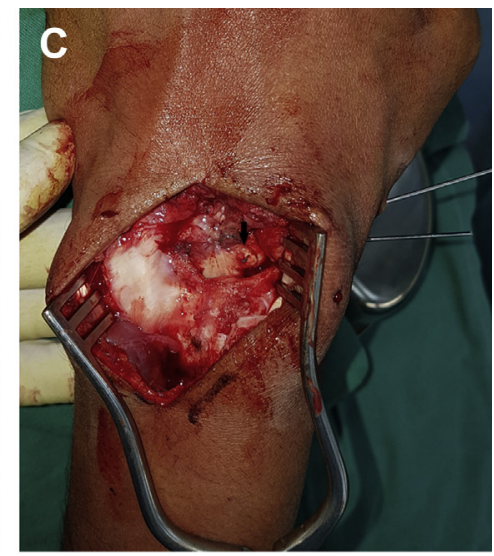

Fig. 8. (A) Acute presentation of a scapholunate ligament injury with a widened interval. $(B)$ Intraoperative view demonstrating scapholunate ligament avulsion (asterisk) from the scaphoid (Sc). The proximal pole of the capitate (C) can be clearly seen. Kirschner wires are used as joysticks to reduce the scapholunate joint. (C) The scapholunate and scaphocapitate joint are pinned before the ligament is repaired to the scaphoid with a suture anchor (black arrow). (D) Radiograph demonstrates a reduced scapholunate interval, appropriate positioning of the wires, and suture anchor. $(E)$ The lateral projection shows an adequately restored scapholunate angle. 
A

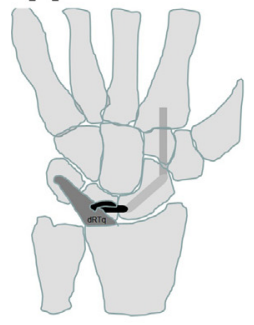

D

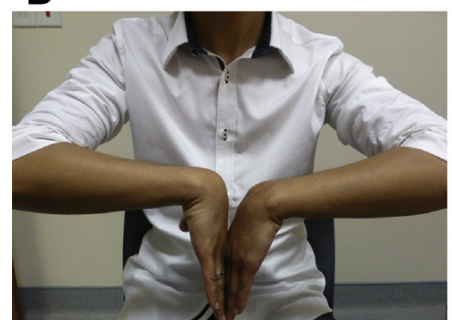

B

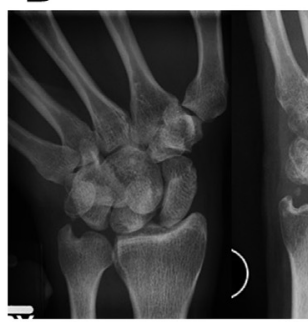

E

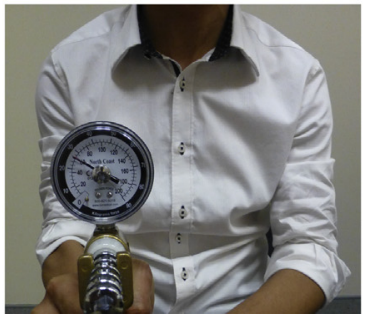

C

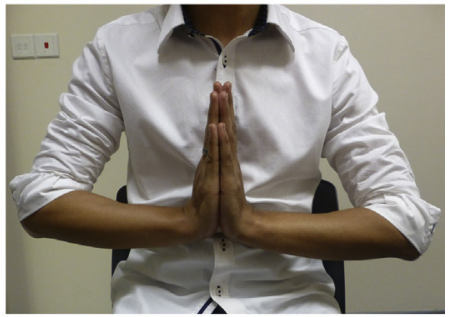

F

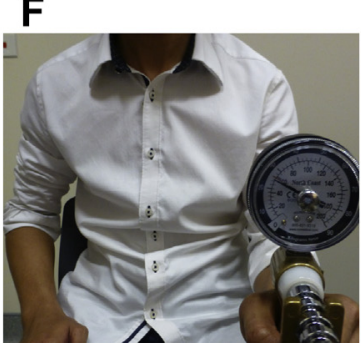

Fig. 9. (A) In this diagrammatic representation, a distally based strip of the flexor carpi radialis is passed from palmar to dorsal through a bone tunnel along the axis of the scaphoid to exit at the normal scaphoid insertion point of the ligament before it is secured to a bone trough on the dorsal lunate, woven into the dorsal radiotriquetral ligament, and secured back to itself. $(B)$ Preoperative films showing a static widened scapholunate interval (left panel) and closure of the gap after tenodesis has been done (centre panel). There still is an abnormal scapholunate angle (right panel). (C-F) Same patient with some stiffness in flexion and extension but satisfied and with good return of grip strength at 1-year follow-up.
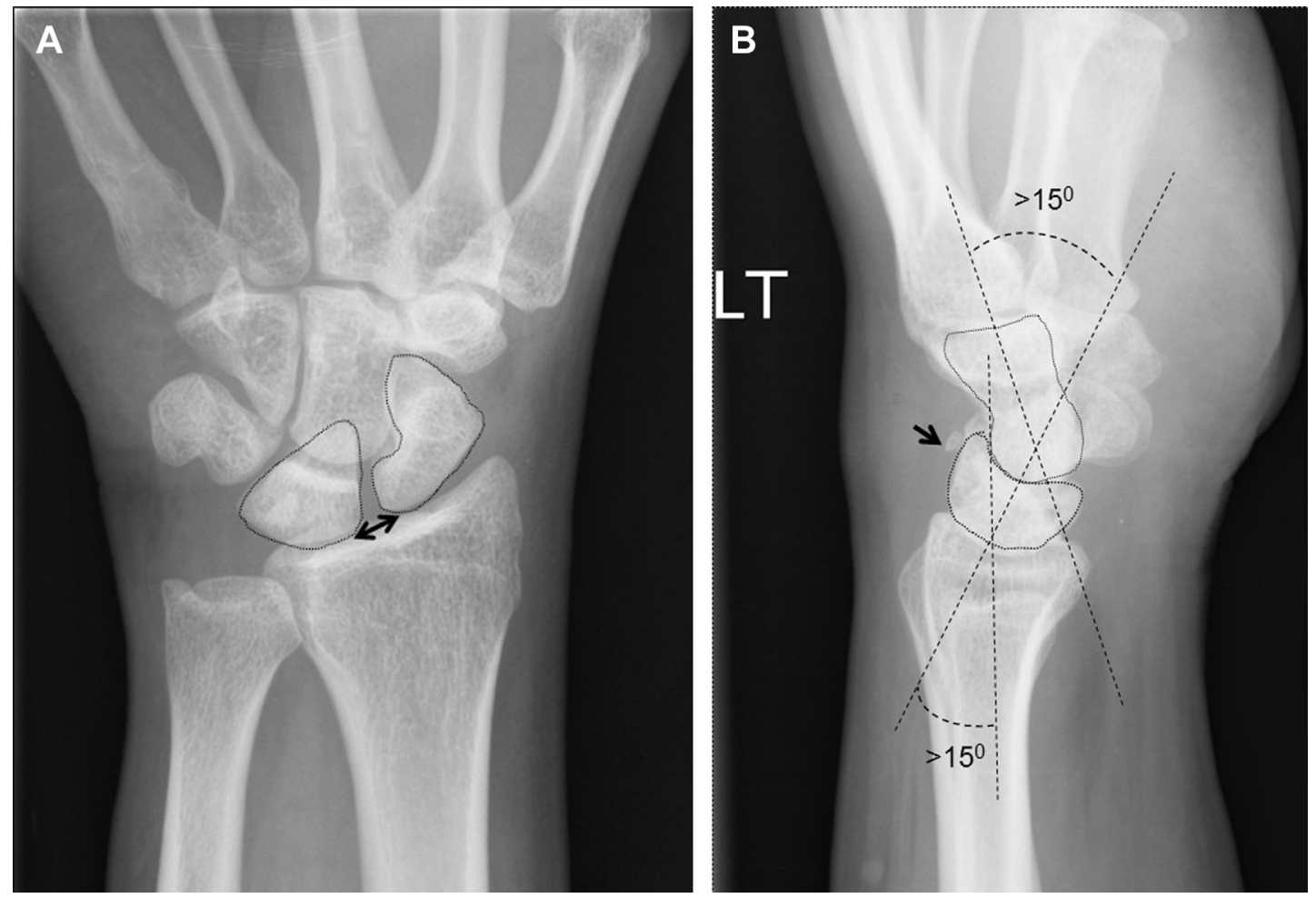

Fig. 10. (A) In lunotriquetral dissociation with a static collapse pattern, the lunate appears triangular, there is a pseudowidening of the scapholunate interval (double-ended arrow), and the scaphoid appears flexed on a PA projection. $(B)$ Lateral views aside from a VISI pattern also may demonstrate an abnormal capitolunate angle as the carpus collapses. The small bony fleck at the dorsal aspect of the carpus (arrow) indicates a dorsal radiotriquetral ligament avulsion. 


\begin{tabular}{|c|c|c|}
\hline \multicolumn{3}{|c|}{$\begin{array}{l}\text { Table } 4 \\
\text { Staging of lunotriquetral instability } \\
\text { (ulnar-sided perilunar instability) by Viegas } \\
\text { and colleagues. }{ }^{15}\end{array}$} \\
\hline Stage & Ligament Disruption & $\begin{array}{l}\text { Radiologic } \\
\text { Findings }\end{array}$ \\
\hline I & $\begin{array}{l}\text { Dorsal lunotriquetral } \\
\text { and membranous } \\
\text { component }\end{array}$ & $\begin{array}{l}\text { Plain } \\
\text { radiographs } \\
\text { normal }\end{array}$ \\
\hline II & $\begin{array}{l}\text { Stage I as well as } \\
\text { palmar } \\
\text { lunotriquetral } \\
\text { ligament }\end{array}$ & $\begin{array}{l}\text { Dynamic VISI } \\
\text { (when palmar } \\
\text { translation } \\
\text { force applied } \\
\text { to dorsum of } \\
\text { capitate with } \\
\text { wrist in } \\
\text { neutral or } \\
\text { flexed } \\
\text { position) }\end{array}$ \\
\hline III & $\begin{array}{l}\text { Stage II and dorsal } \\
\text { radiotriquetral } \\
\text { ligament }\end{array}$ & $\begin{array}{l}\text { Static VISI } \\
\text { deformity } \\
\text { evident }\end{array}$ \\
\hline
\end{tabular}

or in association with degenerative causes, such as ulnocarpal abutment and central TFCC tears, and as part of the perilunate complex injury, to name a few conditions.

Assessment Acute isolated injuries typically result from a backward fall with the hypothenar eminence striking the ground. Tenderness is localized to the lunotriquetral interval with the appearance of a volar sag, and the Reagan ballottement and Kleinman shear tests may be positive. The Reagan ballottement is performed by grasping the pisiotriquetral bones with the thumb and index finger of 1 hand and balloting/ shearing them against the lunate, which is stabilized between the thumb and index finger of the examiner's other hand. Unfortunately, these tests, although sensitive, are not always specific.

Imaging Plain radiographs are normal with partial ligament injuries. With complete disruption of the lunotriquetral ligament complex as well as its extrinsic stabilizer the dorsal radiotriquetral ligament, classic VISI features can be seen on static films (Fig. 10). Traction videofluoroscopy may demonstrate positive findings in complete tears without failure of the extrinsic ligament (Video 4A). High-resolution MRIs may be helpful but the standard for diagnosis remains arthroscopy (Video 4B). Arthritis and a lunotriquetral step are late findings.

Staging and treatment Viegas and colleagues ${ }^{15}$ proposed a staging system for lunotriquetral ligament instability based on biomechanical studies on cadavers, which had a pathomechanical and radiologic correlation (Table 4).

In acute partial injuries (stage I), above-elbow casting or splinting with a pad under the pisiform to boost the triquetrum into correct alignment is prescribed. Even in chronic situations, this should be the first line of treatment. Patients who remain symptomatic may benefit from arthroscopic débridement with or without pinning of the lunotriquetral joint. In some instances, thermal shrinkage may be an effective adjunct (Fig. 11; see Video 4B).
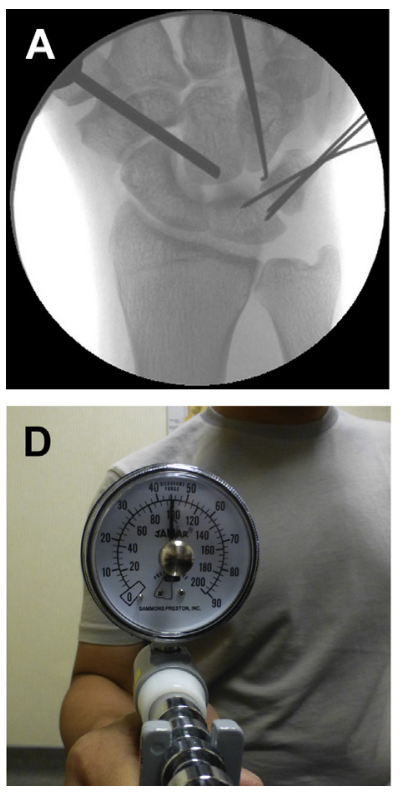
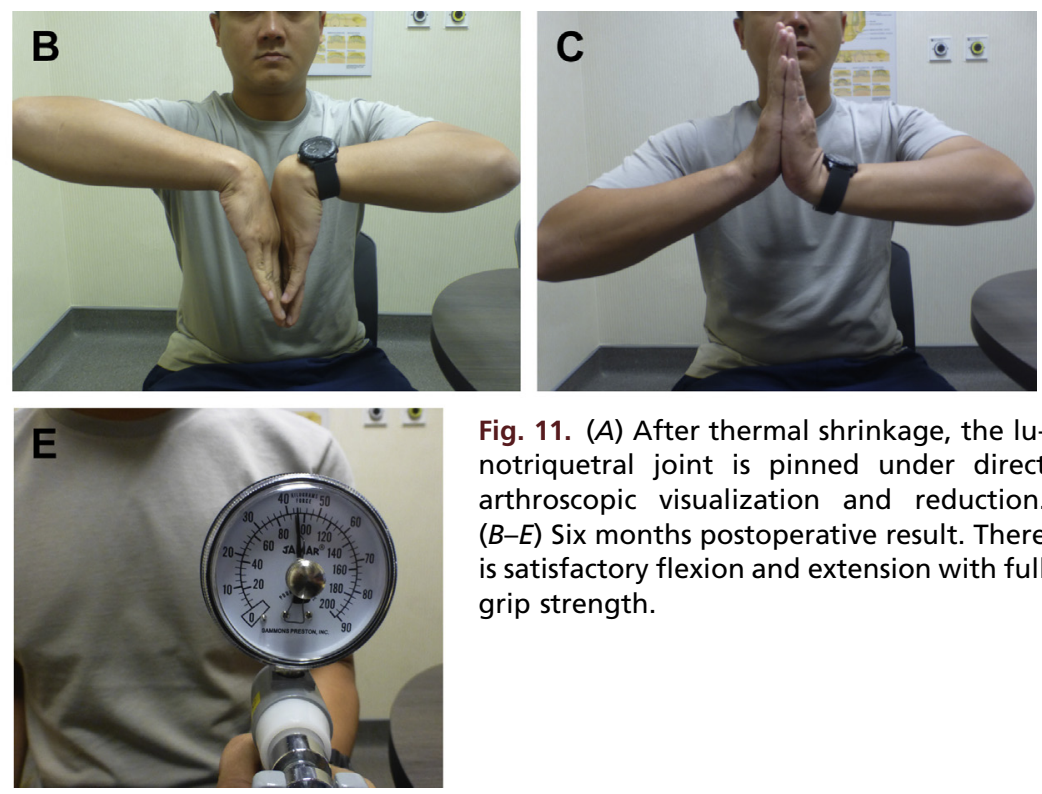

Fig. 11. (A) After thermal shrinkage, the lunotriquetral joint is pinned under direct arthroscopic visualization and reduction. $(B-E)$ Six months postoperative result. There is satisfactory flexion and extension with full grip strength. 

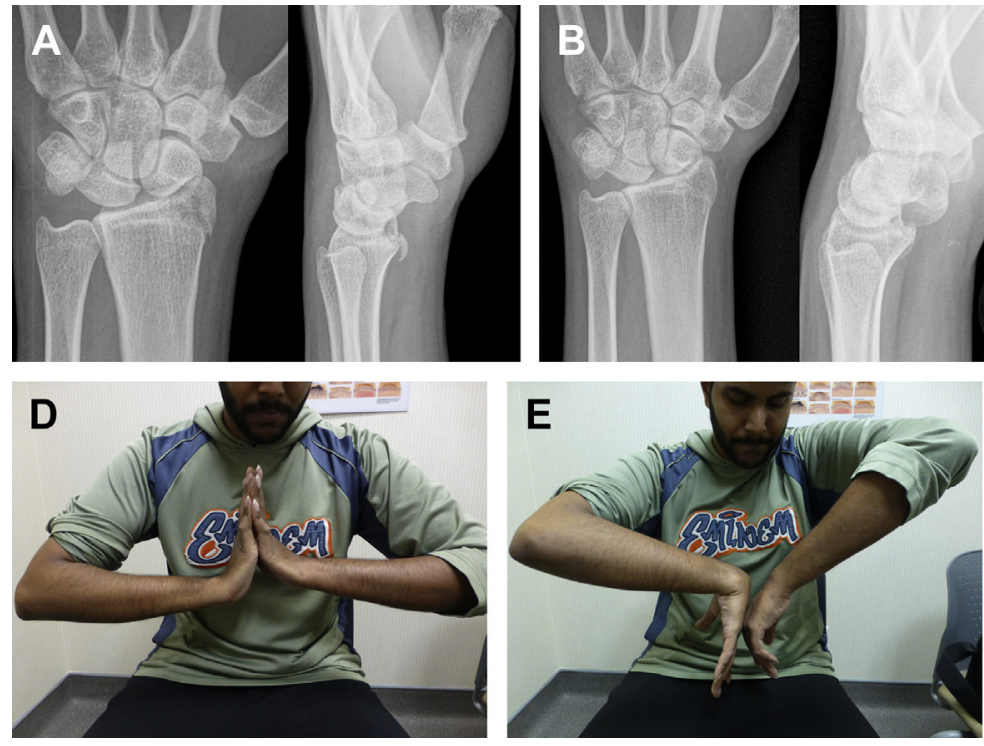

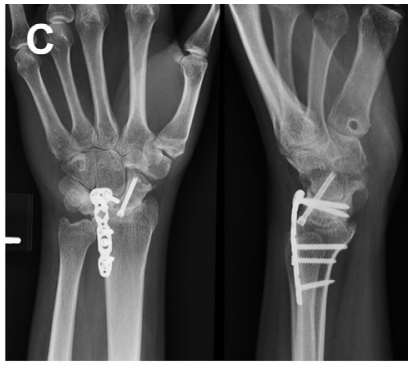

Fig. 12. (A) This patient was believed to have a radial styloid fracture after a motor vehicle accident. At time of presentation, there is already a VISI deformity. $(B)$ Four months later there is progressive carpal collapse with a grossly abnormal capitolunate relationship. (C) Eighteen months status post-radioscapholunate fusion as well as a lunotriquetral fusion with wires and a distal scaphoidectomy. Cartilage loss of the scaphoid necessitated a radioscaphoid fusion. The patient has $(D)$ fair wrist extension and $(E)$ poor wrist flexion. Left panel: posteroanterior projection. Right panel: lateral projection.

In acute stage II injuries, surgical repair and pinning of the lunotriquetral joint for 6 weeks to 8 weeks are indicated. More commonly, diagnosis is delayed and patients may present after several months with chronic ulnar-sided wrist pain and an irreparable ligament. Treatment options then include ligament reconstruction using a distally based strip of the extensor carpi ulnaris ${ }^{16}$, capsulodesis, or lunotriquetral joint fusion. Lunotriquetral fusions, although generally effective, are associated with problems of nonunion ${ }^{16}$ as high as $40 \%$.

In stage III, a global failure of intrinsic and extrinsic ligaments precludes local intercarpal surgical reconstruction strategies. In such uncommon situations, radiolunotriquetral fusion aligns the lunate appropriately with the radius, preserving midcarpal motion (Fig. 12 and Video 5).

\section{Perilunate instability complex}

Perilunate instability complex is the most common wrist dislocation and presents a spectrum of ligamentous and/or bony disruptions to the carpus in 4 enumerated stages (Table 5 ), as described by Mayfield. ${ }^{17}$ The mechanism of injury is wrist axial loading and hyperextension, ulnar deviation, and intercarpal supination. Purely ligamentous injuries are termed lesser arc injuries (Fig. 13A) and those with a fracture greater arc injuries (Fig. 13B). These terms are synonymous with PLD and perilunate fracture dislocation (PLFD), with the most common fracture a scaphoid fracture.
In a multicenter study, ${ }^{18}$ PLDs/PLFDs were associated with higher-energy injuries, frequently seen in polytrauma ( $26 \%$ of cases), and often were missed ( $25 \%$ of cases). PLFDs were twice as common as PLDs, with $97 \%$ of dislocations occurring dorsally (capitate dorsal to lunate) and the most common pattern of injury the dorsal transscaphoid PLFD. Scapholunate ligament tears are seen in a small percentage of transscaphoid PLFDs.

Assessment Aside from the acutely painful and swollen wrist, clinical findings may be subtle and there should be suspicion with a high-energy injury mechanism. Acute median neuropathy may be

\begin{tabular}{|lll|}
\hline \multicolumn{2}{|l|}{ Table 5} & \\
Stages of perilunate dislocation & (Mayfield) ${ }^{17}$ \\
Stage & Ligament Injury & Bony Injury \\
\hline I & $\begin{array}{c}\text { Scapholunate } \\
\text { ligament }\end{array}$ & $\begin{array}{c}\text { Scaphoid } \\
\text { fracture }\end{array}$ \\
\hline II & $\begin{array}{c}\text { Radioscaphocapitate } \\
\text { ligament }\end{array}$ & $\begin{array}{c}\text { Radial styloid } \\
\text { fracture } \\
\text { Capitate } \\
\text { fracture }\end{array}$ \\
\hline III & $\begin{array}{c}\text { Lunotriquetral } \\
\text { ligament }\end{array}$ & $\begin{array}{c}\text { Triquetral } \\
\text { fracture }\end{array}$ \\
\hline IV & $\begin{array}{c}\text { Dorsal radiotriquetral } \\
\text { and radiolunate } \\
\text { ligament }\end{array}$ & $\begin{array}{c}\text { Lunate fracture } \\
\end{array}$ \\
\hline
\end{tabular}



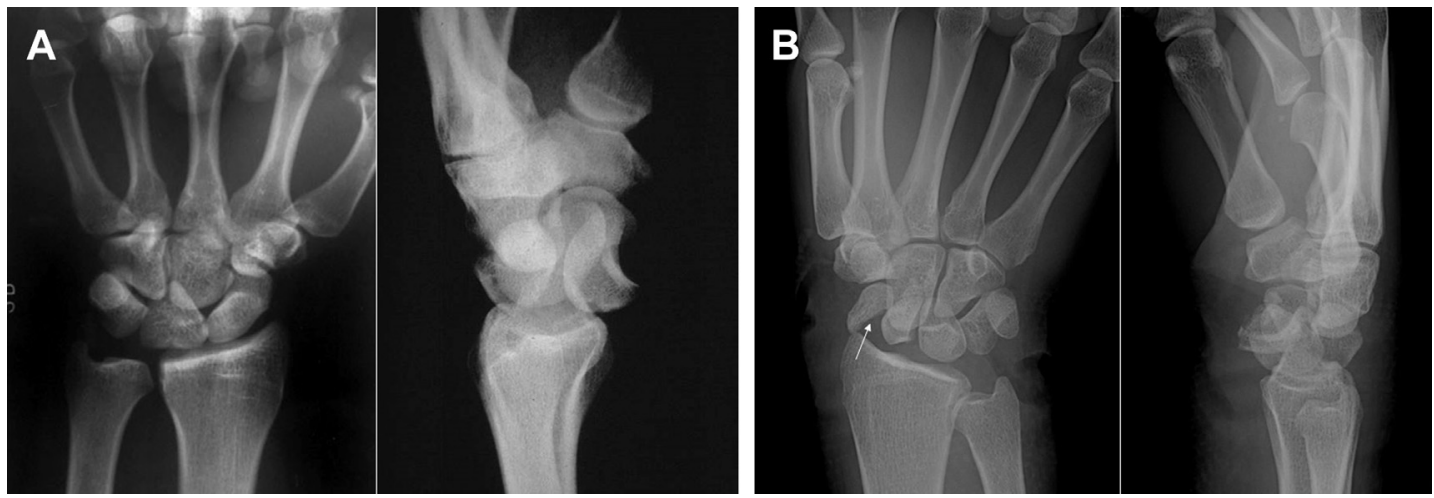

Fig. 13. (A) A lesser arc injury. The lunate appears triangular in shape on the PA view. The lateral view shows the capitate lying dorsally over the lunate, which has been displaced and demonstrates the spilt teacup sign (the teacup being the lunate). ( $B$ ) A greater arc injury with a visible fracture of the scaphoid (white arrow). The overlapping carpal bones of the distal and proximal rows resemble a crowded carpus. Left panel: Posteroanterior projection trauma film. Right panel: Lateral projection trauma film.

present and was reported in $23 \%$ of cases in Herzberg and colleagues' series. ${ }^{18}$

PA wrist projections show the appearance of a crowded carpus and associated fractures, such as the scaphoid (see Fig. 13B) and radial styloid. The lateral projection demonstrates loss of collinearity between the axis of the radius, lunate, and capitate, with the capitate usually dorsal to the lunate. The displaced lunate may give the appearance of a spilt teacup (see Fig. 13A). CT scans are indicated when fractures are suspected.

Treatment Initially, closed reduction by Tavernier method should be attempted. When acute median neuropathy is present, emergent carpal tunnel release should be performed at the time of initial closed reduction in the operating room.

Definitive care is early open reduction and internal fixation of fractures, repair of the ligaments, and intercarpal pinning to maintain alignment and allow the ligamentous injury components to heal (Fig. 14). A single dorsal approach is commonly used, although a volar approach may be indicated, especially if the lunate is dislocated and/ or enucleated and irreducible. The scaphoid screw can be inserted in antegrade fashion if a fracture is present and the dorsal scapholunate

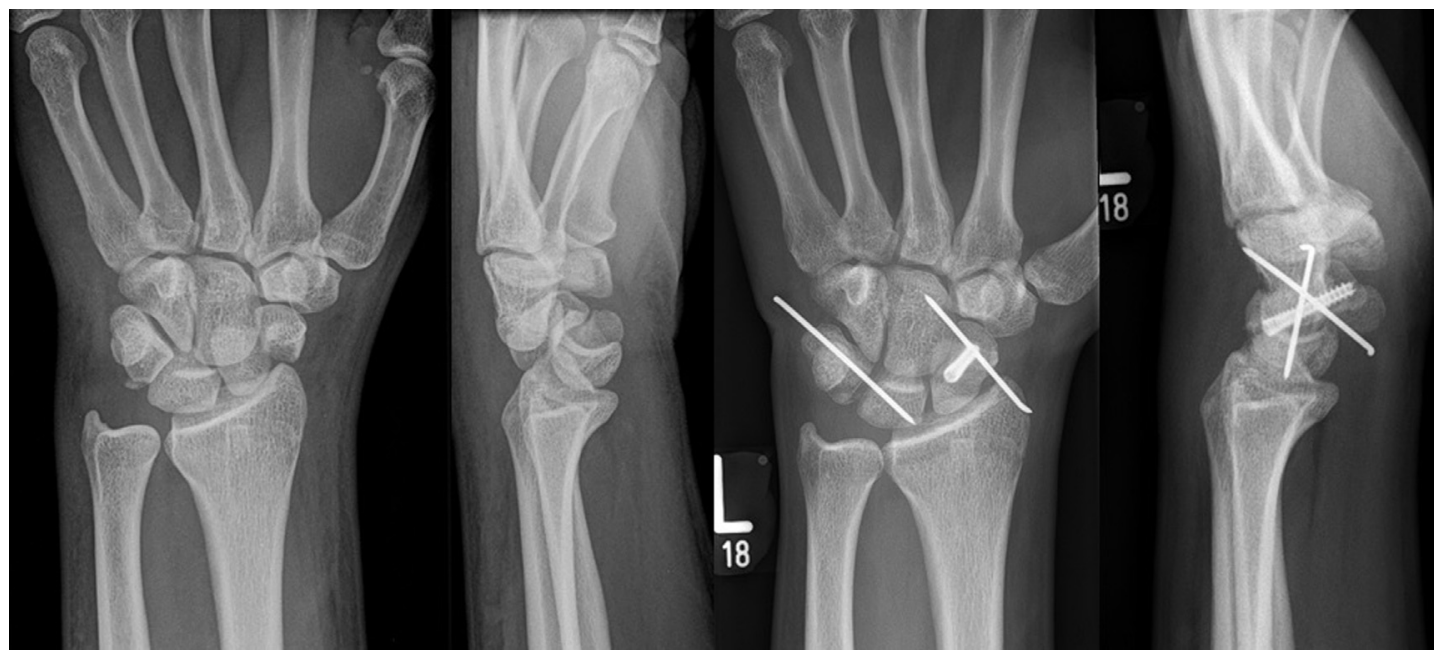

Fig. 14. In this PLFD, both a scaphoid fracture and triquetral avulsion fracture are present. Scaphoid screw fixation and reduction of the lunotriquetral step and pinning of the lunotriquetral joint addresses the lunotriquetral ligament avulsion fracture. Left panel: Posteroanterior projection trauma film. Left middle panel: Lateral projection trauma film. Right middle panel: Posteroanterior projection immediate postoperative film. Right: Lateral projection immediate postoperative film. 


\begin{tabular}{|c|c|c|}
\hline Nontraumatic & Traumatic & $\begin{array}{l}\text { Postsurgical (Instability of Ulna } \\
\text { Stump) }\end{array}$ \\
\hline $\begin{array}{l}\text { - Rheumatoid arthritis } \\
\text { - Connective tissue } \\
\text { disorder (Ehlers-Danlos } \\
\text { syndrome) }\end{array}$ & $\begin{array}{l}\text { - Displaced distal radius fractures } \\
\text { - Basal ulnar styloid fractures } \\
\text { - TFCC injury } \\
\text { - Galeazzi fracture dislocation } \\
\text { - Essex-Lopresti injury } \\
\text { - Both bone forearm shaft } \\
\text { fractures }\end{array}$ & $\begin{array}{l}\text { - Ulna head resection } \\
\text { - Sauvé-Kapandji procedure }\end{array}$ \\
\hline
\end{tabular}

and lunotriquetral ligament can be repaired if injured.

Beyond 6 weeks, the state of cartilage and reparability of the ligaments must be taken into consideration (intraoperative assessment) before performing definitive fixation and ligament repairs. If not possible, a salvage procedure typically in the form of a proximal row carpectomy or a midcarpal arthrodesis are options depending on where the cartilage injury has involved.

\section{DISTAL RADIOULNAR JOINT INSTABILITY}

Distal radioulnar joint (DRUJ) instability can occur either from a variety of causes (Table 6). This review focuses on traumatic and nontraumatic causes, the evaluation, and treatment.

\section{Anatomy and Biomechanics}

Primary stability of the DRUJ is contributed by the congruity of its articular surfaces and the TFCC. ${ }^{19}$ The DRUJ is further reinforced by an osseocartilaginous lip $^{20}$ on the volar aspect of the radius. The secondary stabilizers include the joint capsule, extensor carpi ulnaris, pronator quadratus, and interosseous membrane.

\section{Pathology}

DRUJ instability can be due to either alterations in the bony anatomy, resulting in altered sigmoid notch architecture or abnormal radioulnar relationship, and/or disruptions to the TFCC. DRUJ instability may accompany distal radius fractures due to TFCC disruption or basal ulnar styloid fractures. A fracture of the palmar lunate facet disrupts the buttress effect of the palmar lip and can cause instability. TFCC tears can be traumatic or degenerative $^{21}$ (Table 7). Synovitis in rheumatoid arthritis attrite the stabilizers of the DRUJ, causing instability.

\section{Evaluation}

Patients may present with ulnar-sided wrist pain after a fall on outstretched hand that is usually exacerbated with loading of the wrist in extension, at the extremes of pronation or supination, or after lifting weights. Patients may report clicking and hypermobility.

There may be swelling over the ulnar side of the wrist with a dorsally subluxated ulna head

$$
\begin{aligned}
& \text { Table } 7 \\
& \text { Triangular fibrocartilage complex } \\
& \text { abnormalities } \\
& \text { Class 1- A. Central perforation } \\
& \text { traumatic B. Ulnar avulsion with/ } \\
& \text { without distal ulnar } \\
& \text { fracture } \\
& \text { C. Distal avulsion } \\
& \text { D. Radial avulsion with/ } \\
& \text { without sigmoid notch } \\
& \text { fracture } \\
& \text { Class 2- A. TFCC wear } \\
& \text { degenerative B. TFCC wear } \\
& \text { (ulnocarpal + lunate and/or ulnar } \\
& \text { abutment chondromalacia } \\
& \text { syndrome) C. TFCC perforation } \\
& \text { + lunate and/or ulnar } \\
& \text { chondromalacia } \\
& \text { D. TFCC perforation } \\
& \text { + Lunate and/or ulnar } \\
& \text { chondromalacia } \\
& + \text { Lunotriquetral } \\
& \text { ligament perforation } \\
& \text { E. TFCC perforation } \\
& \text { + Lunate and/or ulnar } \\
& \text { chondromalacia } \\
& + \text { Lunotriquetral } \\
& \text { ligament perforation } \\
& \text { + Ulnocarpal arthritis }
\end{aligned}
$$

Data from Palmer AK. Triangular fibrocartilage complex lesions: A classification. J Hand Surg Am 1989; 14: 594-606 


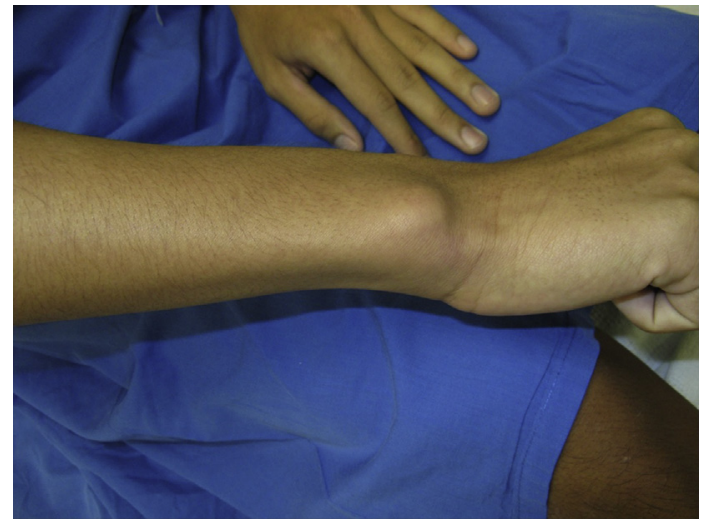

Fig. 15. Prominence of the distal ulna indicating DRUJ subluxation.
(Fig. 15). Pronation and supination are assessed with the elbows held close to the side of the body. The stability of the DRUJ is tested by first stabilizing the radius and carpus with 1 hand and then ballottement of the ulna volarly and dorsally with the wrist held in the neutral, supinated, and pronated position (Video 6) using the uninjured side as a control. Pain on compression of the DRUJ is indicative of synovitis or arthritis.

A true lateral radiograph of the wrist with greater than $50 \%$ uncovering of the ulna head (Fig. 16A) points toward DRUJ instability as does a widened DRUJ interval greater than $3 \mathrm{~mm}$ (Fig. 16B) on a PA projection. Dynamic DRUJ instability can be demonstrated on lateral weight-bearing
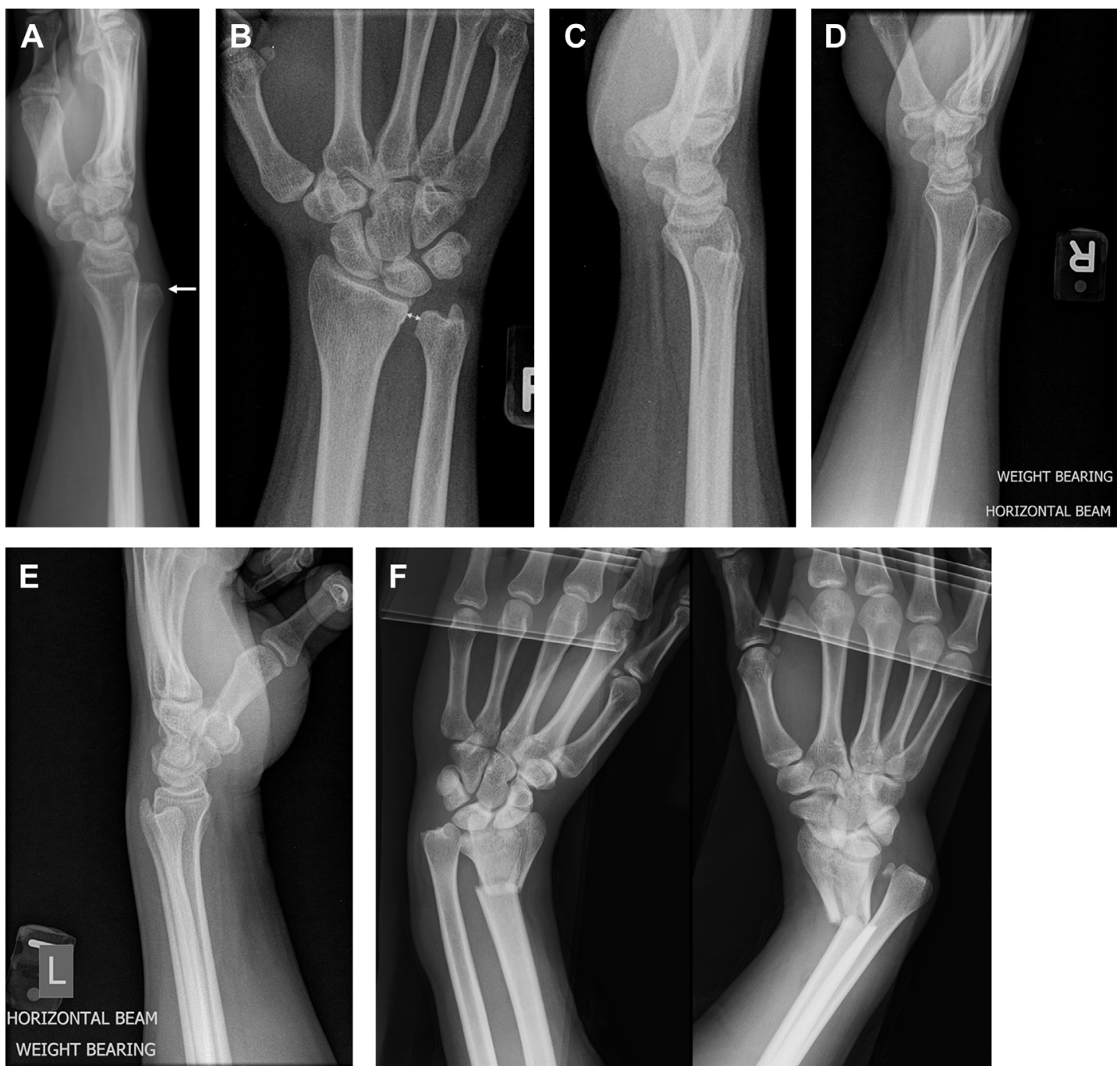

Fig. 16. (A) Significant subluxation of the ulna head (white arrow). (B) Widened DRUJ interval. (double ended arrow). (C) Non-weight-bearing films of symptomatic right DRUJ instability. (D) Lateral weight-bearing film demonstrates gross instability. (E) Opposite wrist lateral weight-bearing film for comparison. (F) Gross displacement of a distal radius fracture at risk of DRUJ instability. 


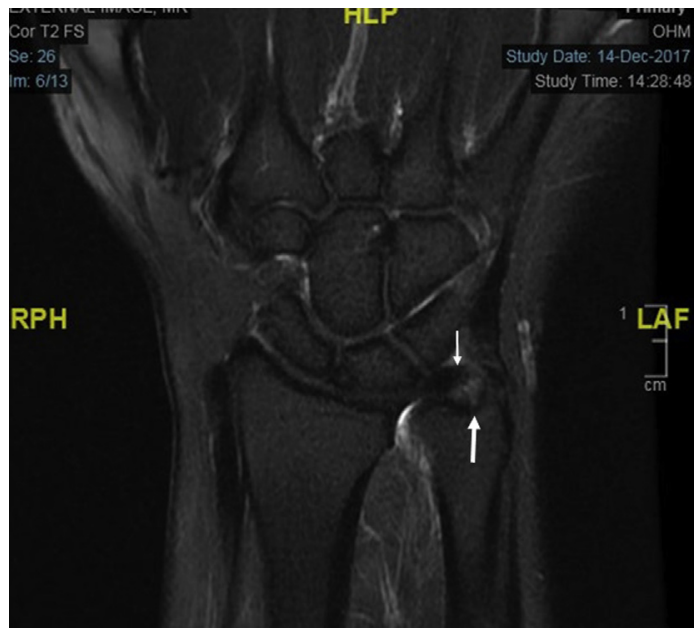

Fig. 17. MRI of the wrist demonstrates a complete TFCC tear (slim arrow) from the fovea (broad arrow).

projections of the wrist suspending $2.27 \mathrm{~kg}$ of weight (Fig. 16C, D) and always should be compared with the opposite side (Fig. 16E). DRUJ instability is an uncommon but important complication of distal radius fractures suggested by a combination of a widened distance between the distal radius and distal ulna, uncovering of the ulna head, and a basal ulna styloid fracture (Fig. 16F). MRIs can delineate foveal and peripheral tears of the TFCC (Fig. 17) as well as assess the state of cartilage in the DRUJ.

\section{Treatment}

An algorithm for surgical options is presented in Fig. 18. Not all patients with DRUJ instability require surgical management, and progression to arthritis is uncommon. ${ }^{22}$ TFCC injuries can occur with injuries to the extensor carpi ulnaris and fractures of the radius and/or ulna bone, and these must be addressed concurrently.

\section{Acute distal radioulnar joint instability}

Nonoperative treatment of acute TFCC injury involves casting or splinting the patient in the position of stability for a period of 6 weeks. In patients with persistent DRUJ instability after fracture reduction or after a trial of nonsurgical treatment, TFCC repair is warranted. This can be done as an open procedure or arthroscopicassisted or arthroscopic capsular repairs. An open repair can be done via an approach between the fifth and sixth extensor compartments. An inversed L-shaped capsulotomy is made (Fig. 19), preserving the dorsal radioulnar ligament. The TFCC is then anchored via bone tunnels or suture anchors.

Arthroscopic methods described include inside-out, outside-in, and all-arthroscopic techniques. Arthroscopy affords better visualization (Video 7) of the TFCC, less injury to surrounding structures, and better wrist motion after surgery. The standard outside-in technique, however, results in prominent suture knots in the subcutaneous layer of the skin, may cause injury

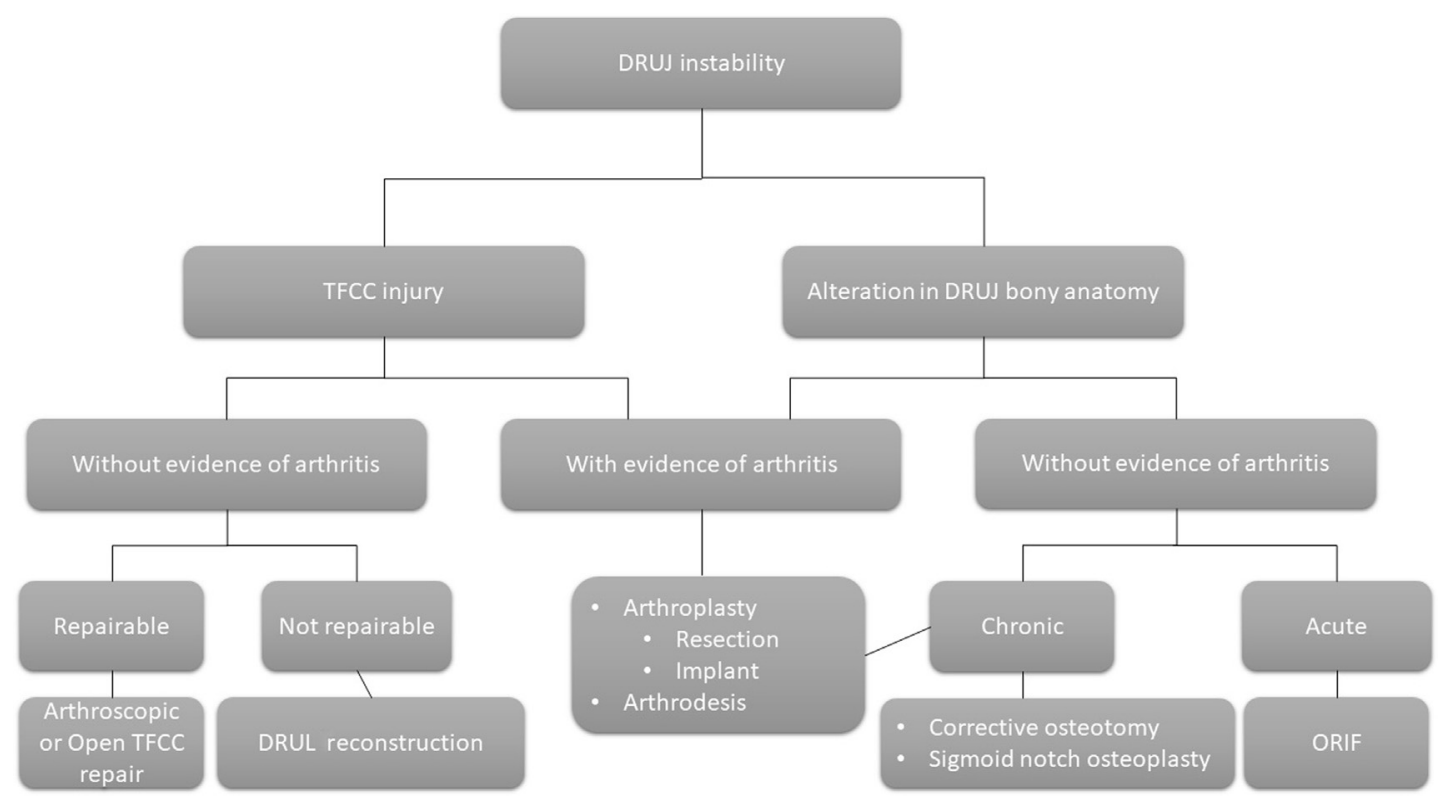

Fig. 18. Treatment algorithm for DRUJ instability. ORIF, Open reduction and internal fixation. 


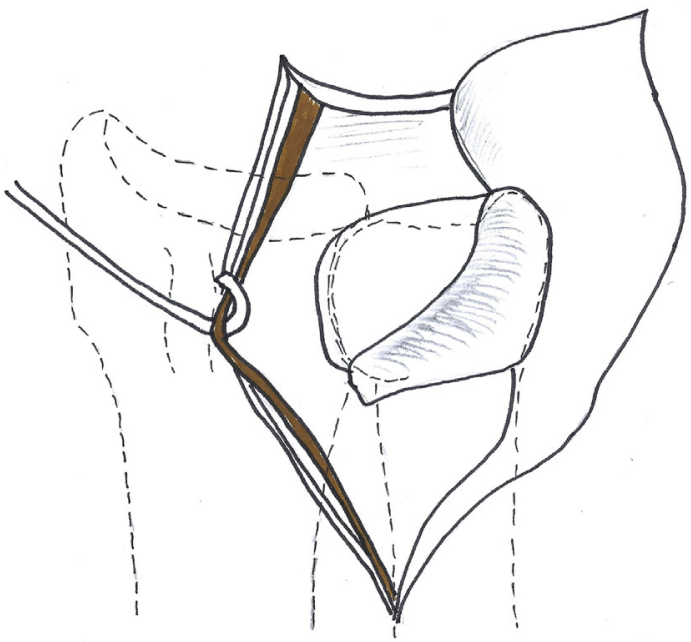

Fig. 19. Dorsal access to the ulnocarpal joint is via a dorsal curvilinear incision over the DRUJ and release of extensor digitiquinti minimi from its compartment before a capsulotomy is made to expose the ulna head and fovea.

to cutaneous nerves, and can be technically demanding. To date, there has been no difference shown in the outcomes between open and arthroscopic repairs. ${ }^{23}$

\section{Chronic distal radioulnar joint instability}

A trial of splinting followed by strengthening of the secondary stabilizers should be attempted for chronic injuries, in addition to nonsteroidal antiinflammatory medications and joint injections. If still symptomatic, TFCC repair can be performed as long as there is adequate substance for repair. ${ }^{24}$ If the TFCC is irreparable, anatomic reconstruction of the distal radioulnar ligament is an option ${ }^{25}$ (Fig. 20) with good long-term outcomes. ${ }^{26}$ Instability secondary to radius or ulnar deformity requires corrective osteotomy with or without a distal radioulnar ligament reconstruction or TFCC repair.

With DRUJ arthritis, salvage procedures either in the form of resection arthroplasty, implant arthroplasty, or arthrodesis procedures are indicated. Resection arthroplasty includes hemiresectioninterposition, matched ulna resection, and distal ulna resection. The Darrach procedure resects the distal ulna with a concurrent procedure to stabilize the ulna stump. The Sauvé-Kapandji procedure (Fig. 21) involves arthrodesis of the DRUJ, with creation of a proximal pseudoarthrosis that maintains the ulnar head in situ and provides support for the carpus.

Semiconstrained total joint prosthesis, such as the Aptis total DRUJ replacement (Aptis Medical, Louisville, KY), is ideal and allows proximal-distal migration of the radius during pronosupination but prevents anterior-posterior motion. Constrained prostheses are not used due to problems with implant loosening.

\section{SUMMARY}

Carpal instability and DRUJ instability may arise from disruption of key ligamentous stabilizers as well as disrupted articular geometry from fractures. Crucial to the management and diagnosis is defining the structures injured and this in turn guides treatment. Radiographs, stress
A

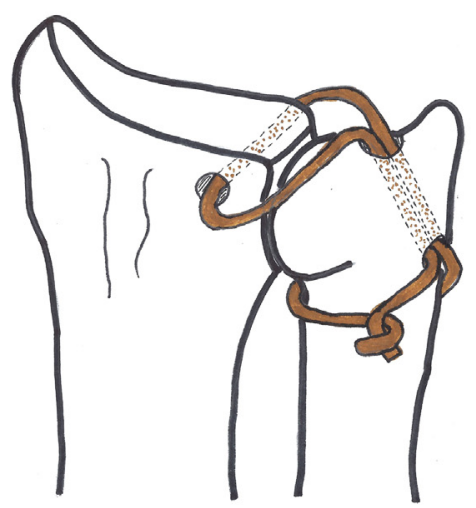

B

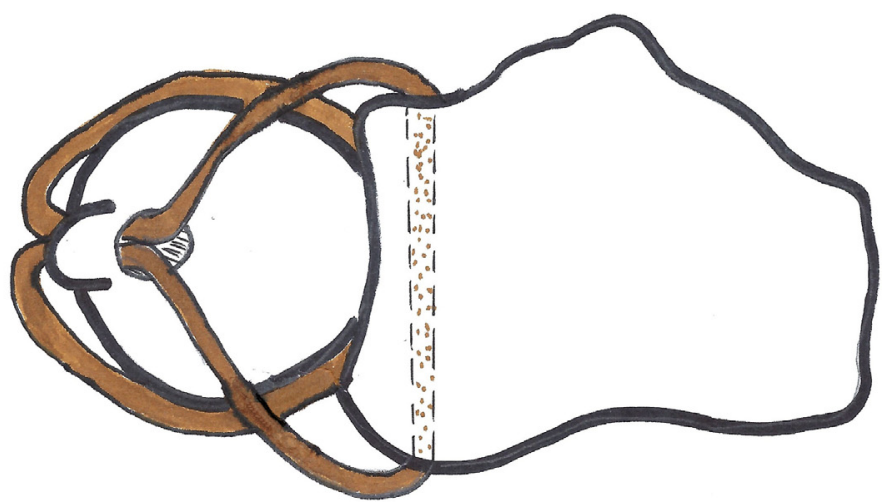

Fig. 20. $(A, B)$ Schematic diagram of 2 described ligament reconstructions. (Adams BD, Berger RA. An anatomic reconstruction of the distal radioulnar ligaments for posttraumatic distal radioulnar joint instability. J Hand Surg Am 2002; 27: 243-251; and Teoh LC, Yam AK. Anatomic reconstruction of the distal radioulnar ligaments: Longterm results. J Hand Surg Br 2005; 30(2): 185-93.) 


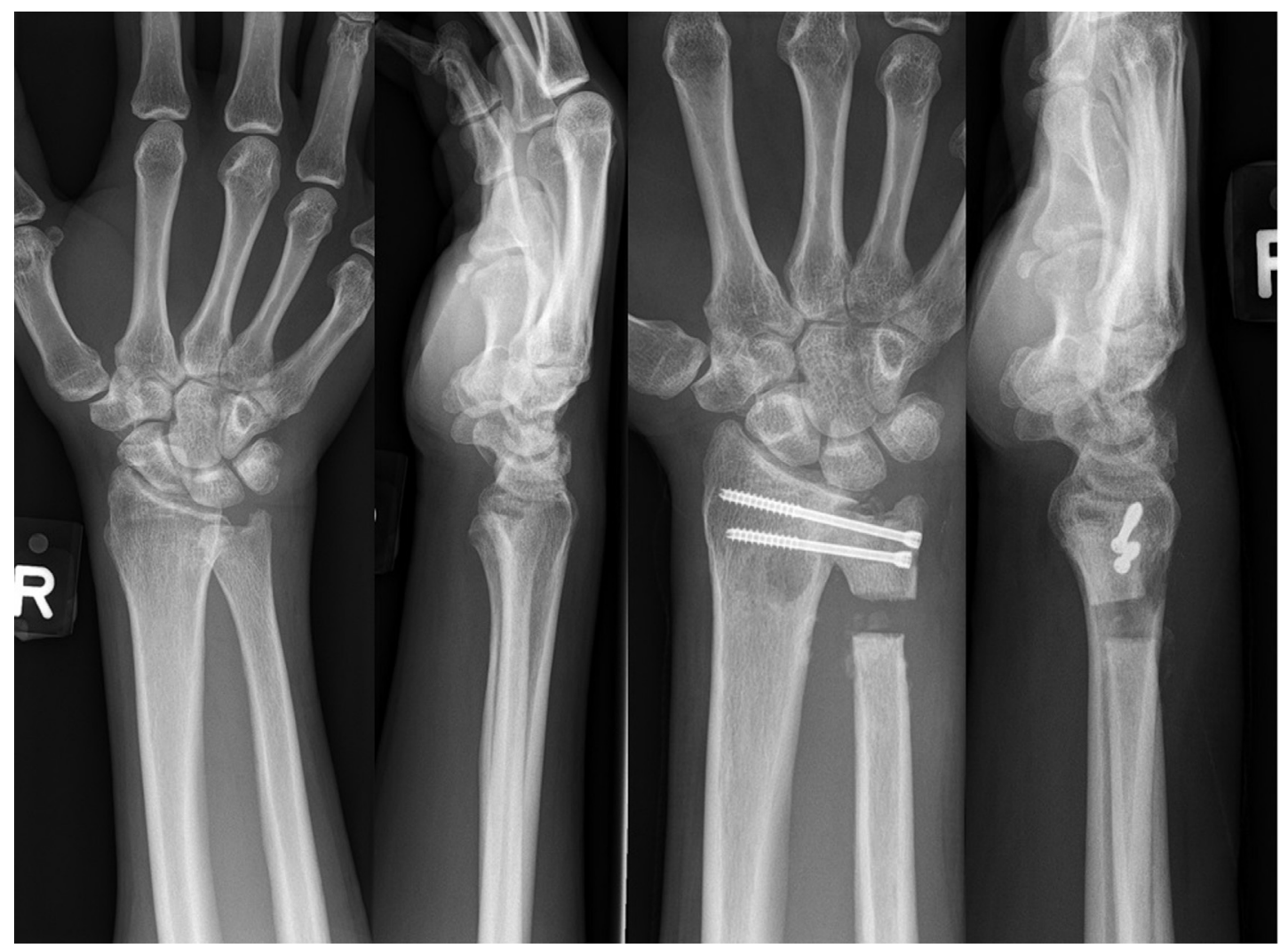

Fig. 21. DRUJ arthritis treated with a Sauvé-Kapandji procedure. Left panel: Posteroanterior film demonstrating DRUJ arthritis. Left middle panel: Lateral film demonstrating volar DRUJ instability. Right middle panel: Status post surgery, posteroanterior film. Right: Status post surgery, lateral film.

radiography, videofluoroscopy, and advanced imaging improve the acuity of diagnosis. Treatment also must be guided by etiology, chronicity of the injury, and severity of the instability.

\section{SUPPLEMENTARY DATA}

Supplementary data related to this article can be found online at https://doi.org/10.1016/j.cps.2019. 03.006.

\section{REFERENCES}

1. Definition of carpal instability. The anatomy and biomechanics committee of the International Federation of Societies for surgery of the hand. J Hand Surg Am 1999;24(4):866-7.

2. Larsen CF, Amadio PC, Gilula LA, et al. Analysis of carpal instability: I. Description of the scheme [review]. J Hand Surg Am 1995;20(5):757-64.

3. Linscheid RL, Dobyns JH, Beabout JW, et al. Traumatic instability of the wrist. Diagnosis, classification, and pathomechanics. J Bone Joint Surg Am 1972;54(8):1612-32.
4. Wright TW, Dobyns JH, Linscheid RL, et al. Carpal instability non-dissociative. J Hand Surg Br 1994; 19(6):763-73.

5. Dobyns JH, Gabel GT. Gymnast's wrist. Hand Clin 1990;6:493-505.

6. Gilula LA. Carpal injuries: analytic approach and case exercises. Am J Roentgenol 1979;133(3):503-17.

7. Watson H, Ottoni L, Pitts EC, et al. Rotatory subluxation of the scaphoid: a spectrum of instability. J Hand Surg Br 1993;18:62-4.

8. Garcia-Elias M, Lluch AL, Stanley JK. Three-ligament tenodesis for the treatment of scapholunate dissociation: Indications and surgical technique. J Hand Surg Am 2006;31:125-34.

9. Geissler WB, Freeland AE, Savoie FH, et al. Intracarpal soft-tissue lesions associated with an intraarticular fracture of the distal end of the radius. J Bone Joint Surg Am 1996;78:357-65.

10. Wahegaonkar AL, Mathoulin CL. Arthroscopic dorsal capsule-ligamentous repair in the treatment of chronic scapho-lunate ligament tears. J Wrist Surg 2013;2:141-8.

11. Moran SL, Ford KS, Wulf CA, et al. Outcomes of dorsal capsulodesis and tenodesis for treatment of 
scapholunate instability. J Hand Surg Am 2006;31: 1438-46.

12. Weiss AP. Scpaholunate ligament reconstruction using a bone-retinaculum-bone autograft. J Hand Surg Am 1998;23:205-15.

13. Pauchard N, Dederichs A, Segret J, et al. The role of three-ligament tenodesis in the treatment of chronic scapholunate instability. J Hand Surg Eur Vol 2012; 38:758-66.

14. Kleinman WB. Long term study of chronic scapholunate instability treated by scaphotrapeziotrapezoid arthrodesis. J Hand Surg Am 1989;14:429-45.

15. Viegas SF, Patterson RM, Peterson PD, et al. UInar-sided perilunate instability: an anatomic and biomechanic study. J Hand Surg Am 1990;15: 268-78.

16. Shin AY, Weinstein LP, Berger RA, et al. Treatment of isolated injuries of the lunotriquetral ligament. A comparison of arthrodesis, ligament reconstruction and ligament repair. J Bone Joint Surg Br 2001;83: 1023-8.

17. Mayfield JK. Patterns of injury to carpal ligaments. A spectrum. Clin Orthop Relat Res 1984;187: 36-42.

18. Herzberg G, Comtet JJ, Linscheid RL, et al. Perilunate dislocations and fracture-dislocations: a multicenter study. J Hand Surg Am 1993;18: 768-79.
19. Hagert E, Hagert CG. Understanding stability of the distal radioulnar joint through an understanding of its anatomy. Hand Clin 2010;26(4):459-66.

20. Tolat AR, Stanley JK, Trail IA. A cadaveric study of the anatomy and stability of the distal radioulnar joint in the coronal and transverse planes. J Hand Surg Br 1996;21(5):587-94.

21. Palmer AK. Triangular fibrocartilage complex lesions: a classification. J Hand Surg Am 1989;14: 594-606.

22. Mrkonjic A, Geijer M, Lindau T, et al. The natural course of traumatic fibrocartilage complex tears in distal radial fractures: a 13-15 year follow-up of arthroscopically diagnosed but untreated injuries. J Hand Surg Am 2012;37(8):1555-60.

23. Anderson ML, Larson AN, Moran SL, et al. Clinical comparison of arthroscopic versus open repair of triangular fibrocartilage complex tears. J Hand Surg Am 2008;33(5):675-82.

24. Hermansdorfer JD, Kleinman WB. Management of chronic peripheral tears of the triangular fibrocartilage complex. J Hand Surg Am 1991;16(2):340-6.

25. Adams BD, Berger RA. An anatomic reconstruction of the distal radioulnar ligaments for posttraumatic distal radioulnar joint instability. J Hand Surg Am 2002;27:243-51.

26. Teoh LC, Yam AK. Anatomic reconstruction of the distal radioulnar ligaments: long-term results. J Hand Surg Br 2005;30(2):185-93. 